\title{
Comparative Analysis of Antiviral Efficacy of Four Different Mouthwashes against Severe Acute Respiratory Syndrome Coronavirus 2: An In Vitro Study
}

\author{
Herb Moskowitz ${ }^{1}$, Michelle Mendenhall ${ }^{2}$
}

\begin{abstract}
Aim: The aim of the present study was to evaluate and compare the efficacy and cytotoxicity of four different mouthwashes containing $1.5 \%$ hydrogen peroxide, $0.2 \%$ povidone, $0.12 \%$ chlorhexidine and $100 \mathrm{ppm}$ molecular iodine for their ability to inactivate severe acute respiratory syndrome coronavirus 2 (SARS-CoV-2).

Materials and methods: The SARS-CoV-2 virus stocks were grown in minimum essential medium (MEM) test media, supplemented with $2.0 \%$ fetal bovine serum (FBS) and $50 \mu \mathrm{g} / \mathrm{mL}$ gentamicin. Test solutions and virus were incubated at room temperature for three contact times of 15 , 30 , and 60 seconds. The solutions were then neutralized by a 1/10 dilution in test media containing $10 \%$ FBS. Neutralized samples were then incubated for 5 days at $37 \pm 2^{\circ} \mathrm{C}$ at $5 \% \mathrm{CO}_{2}$. The test plates were then scored for their cytopathic effect and the log-reduction value (LRV) of the test solution was compared to the negative control (water).

Results: The results showed that the LRV for a $100 \mathrm{ppm}$ molecular iodine oral rinse was significantly greater, at each exposure time, compared with the other three oral rinses in the study with no associated cytotoxicity. The $100 \mathrm{ppm}$ molecular iodine rinse exhibited an LRV of 2.6 at 15 seconds and complete inactivation of SARS-CoV-2 at both 30 seconds and also at 60 seconds with LRV greater than 3.6 for each of those contact times. Conclusion: The spread of infection through aerosol and splatter has long been considered one of the main concerns in the dental community. A preprocedural rinse with 100 ppm molecular iodine will play a vital role in combating COVID-19 pandemic by preventing the spread of infection.

Keywords: COVID, Molecular iodine, Pandemic, Preprocedural.

International Journal of Experimental Dental Science (2020): 10.5005/jp-journals-10029-1209
\end{abstract}

\section{INTRODUCTION}

The 2019 novel coronavirus (SARS-CoV-2) epidemic, which was first reported in December 2019 in Wuhan, China, and has been declared a public health emergency of international concern by the World Health Organization, has progressed to a pandemic associated with substantial morbidity and mortality. ${ }^{1}$ Coronavirus is one of the major pathogens that primarily targets the human respiratory system. Previous outbreaks of coronaviruses (CoVs) include the severe acute respiratory syndrome (SARS)-CoV and the Middle East respiratory syndrome (MERS)-CoV, which have been previously characterized as agents that are a great public health threat. ${ }^{2}$ Viruses do not replicate outside living cells but infectious virus may persist on contaminated environmental surfaces and the duration of persistence of viable virus is affected markedly by temperature and humidity. Contaminated surfaces are known to be significant vectors in the transmission of infections in the hospital setting as well as the community. The main route of transmission of SARS-CoV infection is presumed to be respiratory droplets. ${ }^{3}$ In response to the COVID-19 pandemic, dental offices have instituted unprecedented safeguards to protect patients and staff from viral transmission. A primary concern is the aerosolizing of the SARS-CoV-2 virus associated with dental procedures. ${ }^{4}$ The use of high-speed handpieces, three-way syringes, and ultrasonic scalers all generate dental aerosols. ${ }^{5}$ In order to mitigate the viral load in these aerosols, antimicrobial, preprocedural rinses are recommended. ${ }^{6}$

Therefore, the present in vitro study was designed to evaluate and compare the efficacy of four different mouthwashes containing
${ }^{1}$ Iotech International, Boca Raton, Florida, USA

${ }^{2}$ Institute for Antiviral Research, Utah State University, Utah, USA

Corresponding Author: Herb Moskowitz, lotech International, Boca Raton, Florida, USA, Phone:+1 (561) 509-0205, e-mail:herbmoskowitz@ iotechinternational.com

How to cite this article: Moskowitz H, Mendenhall M. Comparative Analysis of Antiviral Efficacy of Four Different Mouthwashes against Severe Acute Respiratory Syndrome Coronavirus 2: An In Vitro Study. Int J Experiment Dent Sci 2020;9(1):1-3.

Source of support: This study was supported and funded by lotech International, Boca Raton, Florida, USA.

Conflict of interest: Herb Moskowitz is Chairman of lotech International

$1.5 \%$ hydrogen peroxide, $0.2 \%$ povidone, $0.12 \%$ chlorhexidine, and $100 \mathrm{ppm}$ molecular iodine against SARS-CoV-2 and their relative cytotoxicity.

\section{Materials and Methods}

The present study was conducted at the Institute for Antiviral Research (IAR), Utah State University, in a level 3 BioContainment laboratory. The SARS-CoV-2 virus stocks were prepared in the laboratory by growing virus in Vero 76 cells. Test media used was minimum essential media (MEM) supplemented with $2 \%$ fetal bovine serum (FBS) and $50 \mu \mathrm{g} / \mathrm{mL}$ gentamicin. The four mouth rinses used in the study were the following:

I: $3 \%$ hydrogen peroxide (Walgreen Co., Deerfield, Illinois)

II: $10 \%$ povidone iodine (Walgreen Co., Deerfield, Illinois)

(c) The Author(s). 2020 Open Access This article is distributed under the terms of the Creative Commons Attribution 4.0 International License (https://creativecommons. org/licenses/by-nc/4.0/), which permits unrestricted use, distribution, and non-commercial reproduction in any medium, provided you give appropriate credit to the original author(s) and the source, provide a link to the Creative Commons license, and indicate if changes were made. The Creative Commons Public Domain Dedication waiver (http://creativecommons.org/publicdomain/zero/1.0/) applies to the data made available in this article, unless otherwise stated. 
III: $0.12 \%$ chlorhexidine gluconate (Henry Schein Co., Melville, New York)

IV: Formula 100-S molecular iodine (lotech International, Boca Raton, Florida)

Hydrogen peroxide was tested at $1.5 \%$, povidone iodine at $0.2 \%$, chlorhexidine gluconate at $0.12 \%$, and Formula $100-\mathrm{S}$ at 100 ppm molecular iodine. The SARS-CoV-2 virus stock was added to triplicate tubes of each prepared concentration (10\% virus solution plus $90 \%$ test sample). Media only was added to one tube of each prepared concentration to serve as toxicity controls. Ethanol was tested in parallel as a positive control and water only to serve as the virus control. Test solutions and virus were incubated at room temperature for three contact times of 15,30 , and 60 seconds. Following the contact period, the solutions were neutralized by a $1 / 10$ dilution in test media containing $10 \%$ FBS. Neutralized samples were combined for quantification for the average of triplicate tests. Samples were serially diluted using eight half-log dilutions in the test medium. Each dilution was added to four wells of a $96-$-well plate with $80-100 \%$ confluent Vero 76 cells. The toxicity controls were added to an additional four wells and two of these wells were infected with virus to serve as neutralization controls, ensuring that residual sample in the titer assay plated did not inhibit growth and detection of surviving virus. All plates were incubated at $37 \pm 2{ }^{\circ} \mathrm{C}, 5 \% \mathrm{CO}_{2}$. On day 5 after addition of samples, plates were scored for presence or absence of viral cytopathic effect (CPE). The Reed-Muench method was used to determine end-point titers $\left(50 \%\right.$ cell culture infectious dose, $\mathrm{CCID}_{50}$ ) of the samples, and the log-reduction value (LRV) of the compound compared to the negative (water) control was calculated. Virus controls were tested in water and the reduction of virus in test wells compared to virus controls was calculated as the LRV. Toxicity controls were tested with media not containing virus to see if the samples were toxic to cells. Neutralization controls were tested to ensure that virus inactivation did not continue after the specified contact time, and that residual sample in the titer assay plates did not inhibit growth and detection of surviving virus. This was done by adding toxicity samples to titer test plates, then spiking each well with a low amount of virus that would produce an observable amount of CPE during the incubation period.

\section{Results}

Virus titers and LRV for hydrogen peroxide, povidone iodine, chlorhexidine gluconate oral rinse, and Formula 100-S molecular iodine oral rinse are shown in Table 1. Full toxicity was observed in the top three dilutions of hydrogen peroxide $(1 / 10,1 / 100$, and $1 / 1,000$ ) and the top two dilutions of chlorhexidine gluconate oral rinse. Because of this toxicity, presence of virus could not be ruled out in those wells; therefore, the limit of detection was 3.7 and 2.7 $\log _{10} C C I D_{50}$ of virus per $0.1 \mathrm{~mL}$, respectively. The average of virus control samples was used for comparison of test samples and contained $4.3 \log _{10} C C I D_{50}$ per $0.1 \mathrm{~mL}$. Samples with $<1$ log reduction of virus compared to the virus control were not considered active for virucidal activity. Due to cytotoxicity, the virucidal activity of hydrogen peroxide could not be determined as $\geq 1$ log reduction of virus. However, some virus was detected in samples from all time points, indicating no virucidal activity. Povidone iodine exhibited virucidal activity when tested at $0.2 \%$, reducing virus by $2.0(90 \%)$ when combined with virus for a 60 -seconds contact time, but did not reduce by $\geq 1$ log in shorter contact times. lotech International's Formula 100-S molecular iodine oral rinse reduced virus below the limit of detection (LRV > 3.6, >99.9\%) when tested for a contact time of 30 seconds or longer. Further, it reduced virus by 2.6 logs (>99\%) when tested for a 15 -seconds contact time. Neutralization controls demonstrated that residual sample did not inhibit virus growth and detection in the endpoint titer assays in wells that did not have cytotoxicity. Virus controls and positive controls performed as expected.

\section{Discussion}

The oral cavity is a reservoir for a large number of microorganisms including bacteria and viruses. This ecological niche can be a pool for opportunistic and pathogenic microorganisms that can pose a risk for cross-contamination and infection and may even cause systemic infections. This is of particular importance in the case of routine dental practice, as the risk of exposure to microorganisms in the oral cavity is increased due to the open and invasive nature of the procedures. ${ }^{7}$ To better protect patients and staff, dental offices are seeking guidance in augmenting their infection control protocols against SARS-CoV-2. ${ }^{8}$ To a large extent, infection control products have not been directly tested for their efficacy against SARS-CoV-2 because it is extremely contagious. In the United States, in vitro testing on SARS-CoV-2 has only been authorized by the Center for Disease Control and Prevention (CDC) at a limited number of laboratories rated BioContainment Level 3 or higher. ${ }^{9}$ As a result, clinicians are left with well-meaning, but confusing, guidance on the antiviral efficacy of oral rinses against SARS-CoV-2, because no direct testing against the virus had been available. ${ }^{10}$ The American Dental Association has been recommending 1.5\% hydrogen peroxide as a preprocedural rinse because of its antiviral efficacy. At the same time, CDC has published test data showing 18-20 minutes are required for $1.5 \%$ hydrogen peroxide to completely inactivate rhinovirus. ${ }^{8,11}$

The present study directly compares, for the first time, the biocidal efficacy of three widely used oral rinses and a promising new rinse against SARS-CoV-2. These results validate the superior biocidal efficacy of iodine as an antiviral agent against SARS-CoV-2. Both povidone iodine and molecular iodine formula 100-S displayed robust antiviral activity in this study compared to the other rinses.

Table 1: Antiviral efficacy against SARS-CoV-2

\begin{tabular}{|c|c|c|c|c|}
\hline \multirow[b]{2}{*}{ Oral rinse } & \multicolumn{3}{|c|}{ Log reduction value } & \multirow[b]{2}{*}{ Observed cytotoxicity } \\
\hline & 15 seconds & 30 seconds & 60 seconds & \\
\hline $1.5 \%$ hydrogen peroxide & $<1.0$ & $<1.0$ & $<1.0$ & $\begin{array}{l}\text { Present at 1:1,000 } \\
\text { dilution }\end{array}$ \\
\hline $0.2 \%$ povidone iodine & 2.0 & 2.0 & 3.0 & None \\
\hline $0.12 \%$ chlorhexidine gluconate & $<1.0$ & $<1.0$ & 1.0 & Present at 1:100 dilution \\
\hline $\begin{array}{l}\text { lotech international formula } 100-\mathrm{S} \text { (100 } \\
\text { ppm molecular iodine) }\end{array}$ & 2.6 & $\begin{array}{l}>3.6 \text { complete } \\
\text { inactivation }\end{array}$ & $\begin{array}{l}>3.6 \text { complete } \\
\text { inactivation }\end{array}$ & None \\
\hline
\end{tabular}


Table 2: Antiviral efficacy of povidone iodine at varying molecular iodine concentrations

\begin{tabular}{lll}
\hline \multirow{2}{*}{$\begin{array}{l}\text { Measured molecular } \\
\text { iodine concentration }\end{array}$} & \multicolumn{2}{c}{ Log reduction value } \\
\cline { 2 - 3 } & Adenovirus (1 minute) & Poliovirus (15 minutes) \\
\hline $0.17 \mathrm{ppm}$ & 0.6 & 0.6 \\
$1.58 \mathrm{ppm}$ & 2.4 & 2.5 \\
$4.88 \mathrm{ppm}$ & 4.3 & 4.2 \\
\hline
\end{tabular}

lotech International's formula 100-S displayed the greatest antiviral activity of all the tested rinses, completely inactivating SARS-CoV-2 within 30 seconds. The antiviral efficacy of povidone iodine is directly dependent on the concentration of molecular iodine (free iodine) present. A previous study reported that $10 \%$ povidone iodine contains just a few ppm of molecular iodine and that its biocidal efficacy increases, in a dose-dependent fashion, as the concentration of molecular iodine is increased ${ }^{12}$ as summarized in Table 2. The present study results were somewhat compromised by the observed cytotoxicity of both the hydrogen peroxide and chlorhexidine gluconate rinses.

The high rates of transmission, morbidity, and mortality of SARS-CoV- $2^{13}$ suggest that dental offices utilize the most effective measures, possible, to counteract this deadly virus. A preprocedural rinse that can rapidly, safely and effectively knock down viral load, is an important link in this chain of defense. ${ }^{14}$ However, the clear differential in efficacy among the tested rinses highlights the need for an evidence-based approach in the selection of oral rinses. The $100 \mathrm{ppm}$ molecular iodine rinse was recently developed and is based on a unique iodine chemistry. ${ }^{15}$ It was found to be the most effective rinse in reducing viral load in the in vitro lab study.

\section{Conclusion}

The routine use of evidence-based, antiviral, preprocedural rinses should provide both dental patients and dental staff with an additional measure of protection against a uniquely communicable and deadly virus. This in vitro laboratory study demonstrated that iodine-based oral rinses have superior antiviral efficacy with no associated cytotoxicity. Their use preprocedurally will significantly aid in controlling cross-infection in closed dental settings. However, further investigation of their antiviral applications and more studies in clinical settings are needed.

\section{References}

1. Zou L, Ruan F, Huang M, et al. SARS-CoV-2 viral load in upper respiratory specimens of infected patients. N Engl J Med 2020;382(12):1177-1179. DOI: 10.1056/NEJMc2001737.

2. Rothan HA, Byrareddy SN. The epidemiology and pathogenesis of coronavirus disease (COVID-19) outbreak. J Autoimmun 2020;109:102433. DOI: 10.1016/j.jaut.2020.102433.

3. Chan KH, Peiris JS, Lam SY, et al. The effects of temperature and relative humidity on the viability of the SARS coronavirus. Adv Virol 2011;2011:734690. DOI: 10.1155/2011/734690.

4. Interim Infection Prevention and Control Guidance for Dental Settings During the Coronavirus Disease 2019 (Covid-19) Pandemic. Centers for Disease Control and Prevention. Retrieved on August 4, 2020 from https://www.cdc.com.

5. Harrel SK. Dental aerosols and spatter amidst COVID-19. Decis Dentis 2020;6(5):8-11.

6. Booth J, Reducing aerosol viral load to minimize spread of SARSCoV-2 in dental clinics. Dental Tribune. Retrieved on April 21, 2020 from https://www.dental-tribune.com.

7. Saini R. Chlorine dioxide: an ideal preprocedural mouthrinse in dental set-up. Eur J Gen Dent 2015;4(3):113-116. DOI: 10.4103/22789626.163321.

8. Covid-19 Infection Control Protocol and Procedures. American Dental Association Online courses. Retrieved on March 20, 2020 from https:// www.ada.org.

9. McLeod V, Biosafety Levels 1,2,3 and 5. Retrieved on December 8, 2020 from https://www.labmanager.com.

10. Wang $\mathrm{H}, \mathrm{Li} X, \mathrm{Li}$, et al. The genetic sequence, origin, and diagnosis of SARS-CoV-2. Eur J Clin Microbiol Infect Dis 2020;39(9):1629-1635. DOI: 10.1007/s10096-020-03899-4.

11. Guidelines for Disinfection and Sterilization in Healthcare Facilities. Centre for disease Control and Prevention 2008. Retrieved from https://www.cdc.gov/infectioncontrol/guidelines/disinfection/ index.html.

12. Wada H, Nojima Y, Ogawa S, et al. Relationship between virucidal efficacy and free iodine concentration of povidone-iodine in buffer solution. Biocontrol Sci 2016;21(1):21-27. DOI: 10.4265/bio.21.21.

13. Center for Disease Control and Prevention. Retrieved on August 21, 2020 from https://cdc.gov/coronavirus/2019-ncov/cases-updates/ us-cases-deaths.

14. Hendrick LG. Recommendations for the dental practice in response to COVID-19. RDH Magazine 2020. 14169838.

15. Iotech International, Boca Raton, Florida. Stable Compositions of Uncomplexed lodine and Methods of Use. U.S. Pat. Appl.10092006, 2018. 